\title{
Foramen Magnum: A Morphological and Morphometric Study in Dried Human Skull Bones of Rajasthan Population and its Surgical Importance
}

\author{
Devesh K Sharma ${ }^{1}$, Simmi Mehra²
}

\section{Abstract}

Introduction: The foramen magnum (FM) is a large opening in the base of the skull. The dimensions of FM are clinically important because many vital structure passing through it, viz., the lower end of medulla oblongata, the vertebral arteries, and spinal accessory nerves. It may endure compression such as in cases of FM herniation, FM meningiomas, and FM achondroplasia. The knowledge of FM diameter is needed to determine some malformations such as the Arnold-Chiari syndrome, which shows expansion of the transverse diameter.

Materials and methods: The present study was carried out on 75 dry human skulls of unknown age and sex belonging to Rajasthan population by the Department of Anatomy at Mahatma Gandhi Medical College and Hospital, Jaipur, Rajasthan. All the measurements were taken with the help of digital vernier calipers.

Results: The mean anteroposterior diameter was $35.11 \pm 3.12 \mathrm{~mm}$, the transverse diameter was $29.35 \pm 3.48 \mathrm{~mm}$, area was $813.94 \pm 146.40 \mathrm{~mm}{ }^{2}$, and the FM index was $1.208 \pm 0.150$. The FM shapes were determined as oval (22.67\%), egg-shaped $(12.00 \%)$, round $(14.67 \%)$, tetragonal (14.67\%), pentagonal (9.33\%), hexagonal (16.00\%), and irregular (10.67\%).

Conclusion: This study will be useful for the anatomists, radiologists, neurosurgeons, and orthopedic surgeons.

Keywords: Achondroplasia, Arnold-Chiari syndrome, Foramen magnum.

Journal of Mahatma Gandhi University of Medical Sciences \& Technology (2018): 10.5005/jp-journals-10057-0075
\end{abstract}

\section{INTRODUCTION}

The foramen magnum (FM) is a large opening (Latin: great hole) in the base of the skull (Fig. 1). It is an important landmark of the base of skull and is of particular interest for anthropologists, anatomists, forensic medicine, neurosurgeons, and radiologists.

The FM is surrounded by different parts of the occipital bone that has two condylar parts, the squamous part and the occipital part.

The squamous part lies behind and above, basilar part in front, and a condylar part on either side. ${ }^{1}$

\section{Border of Foramen Magnum}

The anterior border of FM is formed by the basilar process of the occipital bone, the lateral border by left and right ex-occipitalis, and the posterior border is formed by the supraoccipital part of the occipital bone. ${ }^{2}$

The upper ends of anterior and posterior atlanto-occipital membranes are attached to the FM at its anterior and posterior margins, respectively, and their lower ends are attached to the superior surface of anterior and posterior arch of the atlas, respectively. ${ }^{3}$

Many authors have classified FM based on its shape, viz., oval, egg-shaped, round, tetragonal, pentagonal, hexagonal, and irregular. $^{4-6}$

The FM is a wide communication between the posterior cranial fossa and the vertebral canal.

The alar ligament of dens divides the foramen into anterior "Osseo-ligamentous compartment" and posterior "Neurovascular compartment."

Both upper fasciculus of the cruciate ligament and membranatectoria are attached to the upper surface of basioccipital bone in front of the FM.
1,2Department of Anatomy, Mahatma Gandhi Medical College and Hospital, Jaipur, Rajasthan, India

Corresponding Author: Simmi Mehra, Department of Anatomy, Mahatma Gandhi Medical College and Hospital, Jaipur, Rajasthan, India, Phone: +91 9929399941, e-mail: Mehrasimmi61@yahoo.com

How to cite this article: Sharma DK, Mehra S. Foramen Magnum: A Morphological and Morphometric Study in Dried Human Skull Bones of Rajasthan Population and its Surgical Importance. J Mahatma Gandhi Univ Med Sci Tech 2018;3(2):41-49.

Source of support: Nil

Conflict of interest: None

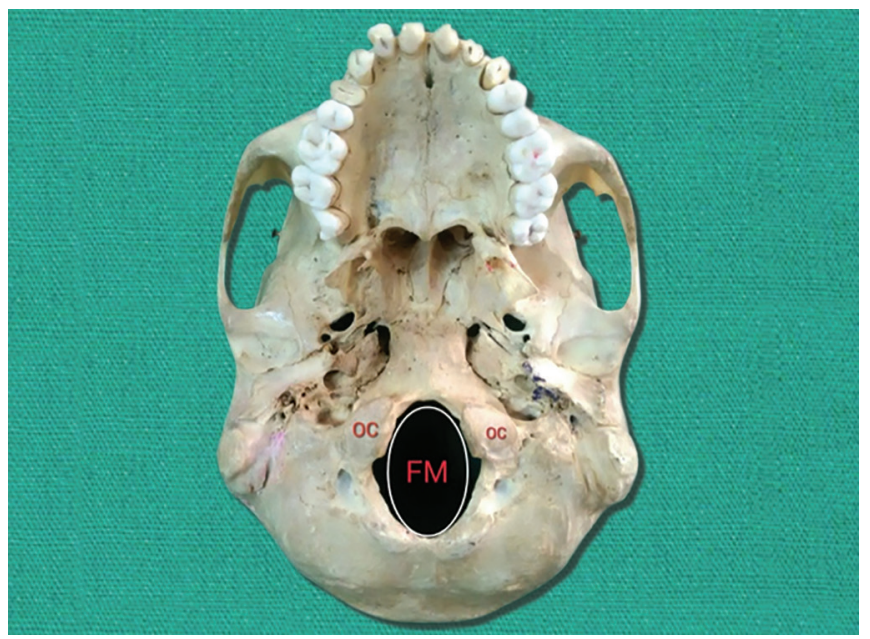

Fig. 1: Norma basalis view showing foramen magnum and occipital condyles

o The Author(s). 2018 Open Access This article is distributed under the terms of the Creative Commons Attribution 4.0 International License (https://creativecommons. org/licenses/by-nc/4.0/), which permits unrestricted use, distribution, and non-commercial reproduction in any medium, provided you give appropriate credit to the original author(s) and the source, provide a link to the Creative Commons license, and indicate if changes were made. The Creative Commons Public Domain Dedication waiver (http://creativecommons.org/publicdomain/zero/1.0/) applies to the data made available in this article, unless otherwise stated. 
Its wide posterior part contains the medulla oblongata and its meninges. In the subarachnoid space, spinal rami of the accessory nerve and vertebral arteries with their sympathetic plexus ascend into the cranium.

The posterior spinal arteries descend posterolateral to the brain stem, whereas the anterior spinal artery descends anteromedian to the brain stem. The cerebellar tonsils may project into the FM. ${ }^{7}$ The dimensions of the FM are clinically important because the abovementioned vital structures passing through it may endure compression such as in cases of FM herniation, FM meningiomas, and FM achondroplasia.

The transverse diameter of FM will be increased in the ArnoldChiari syndrome. ${ }^{8-10}$

The evaluation of morphometric of FM is helpful for forensic dentistry and medicine. ${ }^{11}$

The progress in the neuroimaging techniques to diagnose craniovertebral abnormalities accurately has enhanced the field of craniovertebral surgery. Such surgeries are a challenging task for the neurosurgeons because of the close relation of vascular and neural structures within the FM. Advances in skull base surgeries such as the "far lateral transcondylar approach" have improved the better and wider access of surgical exposure leading to successful surgeries in this region. To perform such surgeries, prior analysis of the morphometric dimensions of FM is essential. ${ }^{12}$

The present study aims at collecting morphological and morphometric data on FM, which might help neurosurgeons to plan surgeries and add to the preexisting literature on FM.

\section{Materials and Methods}

The study was conducted on 75 adult dry human skulls of unknown age and sex belonging to Rajasthan population by the Department

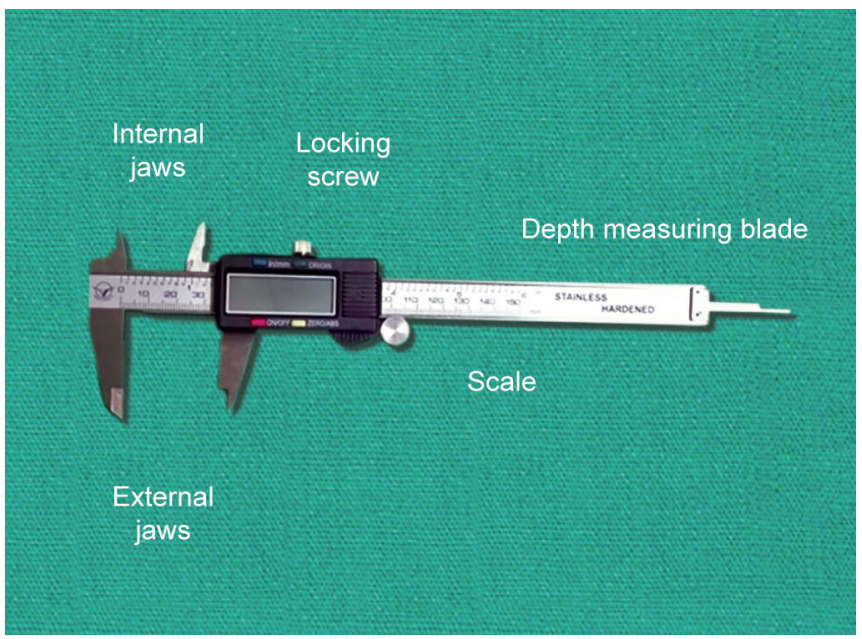

Fig. 2: Digital vernier calipers
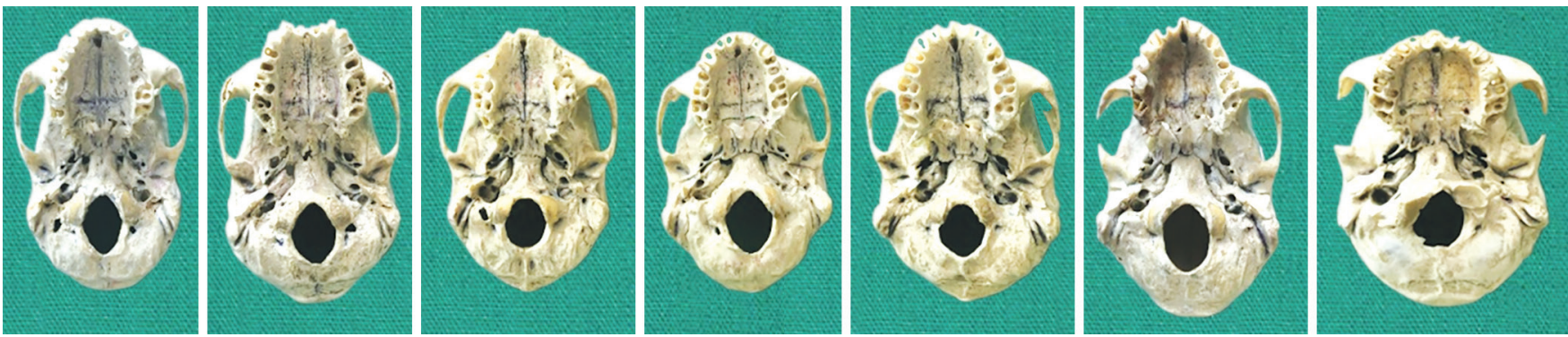

of Anatomy of Mahatma Gandhi Medical College, Jaipur, and Sawai Man Singh Medical College, Jaipur.

All the measurements were taken with the help of digital vernier calipers (Fig. 2).

Following metric parameters were noted:

- Shapes ofFM:The different shapes of the FM were macroscopically noted and classified according to Zaidi et al. as oval, egg-shaped, round, tetragonal, pentagonal, hexagonal, and irregular (Fig. 3).

- Anteroposterior diameter (APD): It is the distance between basion (midpoint of the anterior margin of the FM) and opisthion (midpoint of the posterior margin of the FM) (Fig. 4).

- Transverse diameter (TD): It is the distance between the lateral margins of the FM at the point of greatest lateral curvature (Fig. 5).

- Foramen magnum index (FMI): It is calculated by dividing the anteroposterior diameter by the transverse diameter (APD/TD).

$\pi=$ pi $(22 / 7$ or 3.14$)$

$W=$ width (transverse diameter)

$L=$ length (anteroposterior diameter)

Hence, area will be calculated as follows:

Area of FM $=1 / 4 \times \pi \times$ transverse diameter $\times$ anteroposterior diameter

\section{Results}

The morphological and morphometric observations of the FM in 75 dried human skulls belonging to Rajasthan population are as follows (Table 1):

The most common shape was oval (22.67\%) and the least common shape was pentagonal (9.33\%) (Fig. 6).

The mean anteroposterior diameter was $35.11 \pm 3.12 \mathrm{~mm}$. The maximum anteroposterior diameter was $43.14 \mathrm{~mm}$ and the minimum anteroposterior diameter was $27.01 \mathrm{~mm}$ observed in the present study (Table 2).

The mean transverse diameter was observed to be $29.35 \pm$ $3.46 \mathrm{~mm}$. The maximum transverse diameter was $38.11 \mathrm{~mm}$, and the minimum transverse diameter was $25.49 \mathrm{~mm}$.

The mean values of APD and TD are represented in the form of bar diagrams (Fig. 7).

In the present study, the mean value of FM index was found to be 1.208 , with minimum value of 0.969 and maximum being 1.740 with standard deviation of $0.150 \mathrm{~mm}$ for 75 specimens (Table 3 ).

When the FMI is greater than 1.2, the foramen is found to be ovoid (Radhika et al.) (Table 4).

Around $45.33 \%$ of skulls studied exhibited an ovoid FM.

The mean value of area of FM was calculated to be $813.94 \pm$ $146.40 \mathrm{~mm}^{2}$. The maximum area was $1105.70 \mathrm{~mm}^{2}$, and the minimum area was $559.54 \mathrm{~mm}^{2}$ (Table 5).
- Area of FM by Radinsky's formula: $A=1 / 4 \times \pi \times W \times L$

Fig. 3: Shapes of foramen magnum 


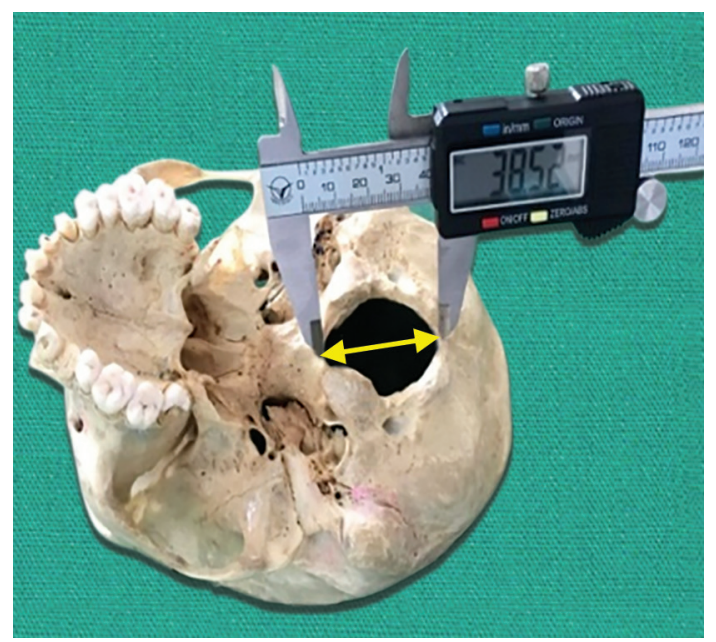

Fig. 4: Anteroposterior diameter

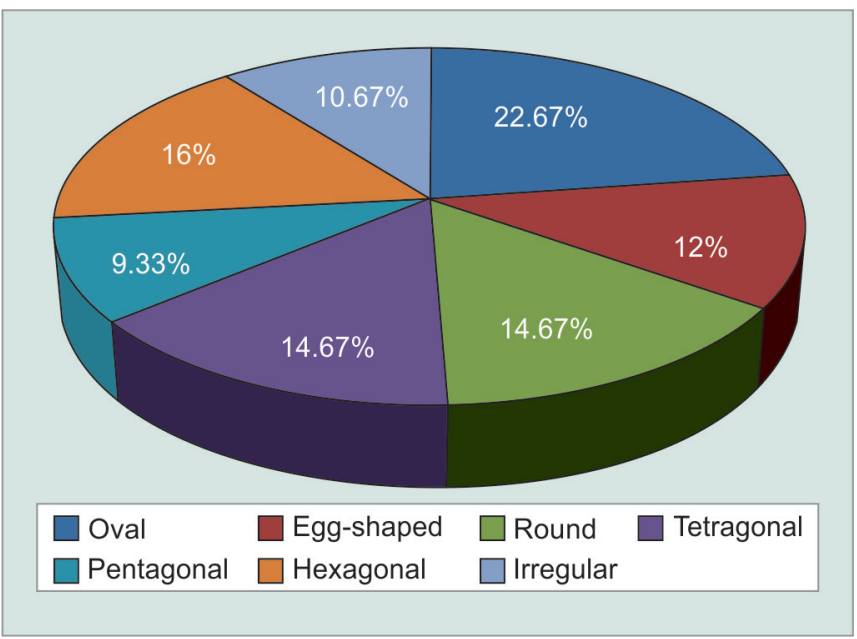

Fig. 6: Percentage of various shapes of the foramen magnum

Table 1: Number and percentages of various shapes of the FM

\begin{tabular}{lll}
\hline \multicolumn{3}{c}{ No. of specimens } \\
Shapes of FM & $(n=75)$ & Percentage \\
\hline Oval & 17 & 22.67 \\
Egg-shaped & 9 & 12.00 \\
Round & 11 & 14.67 \\
Tetragonal & 11 & 14.67 \\
Pentagonal & 7 & 9.33 \\
Hexagonal & 12 & 16.00 \\
Irregular & 8 & 10.67 \\
\hline
\end{tabular}

Table 2: Anteroposterior diameter and transverse diameter

\begin{tabular}{lll}
\hline Parameter & APD $(\mathrm{mm})$ & $T D(\mathrm{~mm})$ \\
\hline Minimum & 27.01 & 25.49 \\
Maximum & 43.14 & 38.11 \\
Mean & 35.11 & 29.35 \\
Standard deviation & 3.12 & 3.48 \\
\hline
\end{tabular}

\section{Discussion}

In the present study, oval-shaped FM was the commonest shape, which is comparable to findings of researchers of ethnic groups, Kumar et al., Piras et al., and Pelinllhan et al. (Table 6).

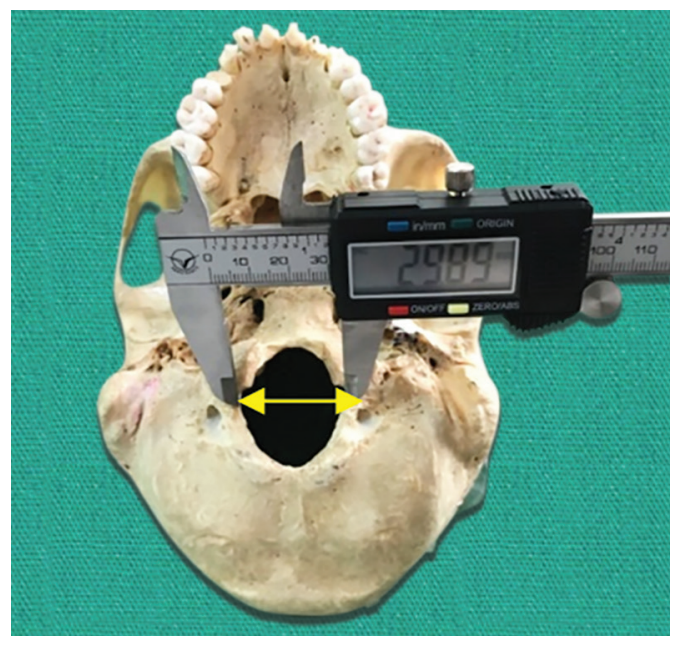

Fig. 5: Transverse diameter

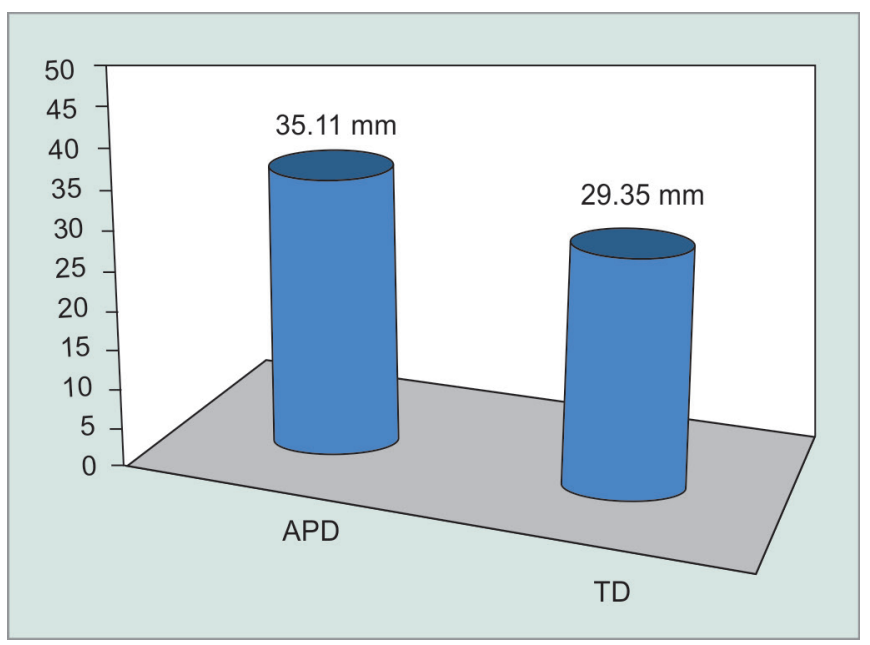

Fig. 7: Mean value of anteroposterior diameter and transverse diameter

Table 3: Foramen magnum index

\begin{tabular}{ll}
\hline Parameters & FMI \\
\hline Minimum & 0.969 \\
Maximum & 1.740 \\
Range & $0.969-1.740$ \\
Mean & 1.208 \\
Standard deviation & 0.150 \\
\hline
\end{tabular}

Table 4: Frequency and percentage of FMI

\begin{tabular}{llc}
\hline $\begin{array}{l}\text { Foramen magnum } \\
\text { index (FMI) }\end{array}$ & Frequency & Percentage \\
\hline$<1.20$ & 41 & 54.67 \\
$\geq 1.20$ & 34 & 45.33 \\
Total & 75 & 100 \\
\hline & \\
Table 5: Area of FM & \\
\hline Parameter & Area $\left(\mathrm{mm}^{2}\right)$ \\
\hline Minimum & 559.54 \\
Maximum & 1105.70 \\
Mean & 813.94 \\
Standard deviation & & 146.40 \\
\hline
\end{tabular}




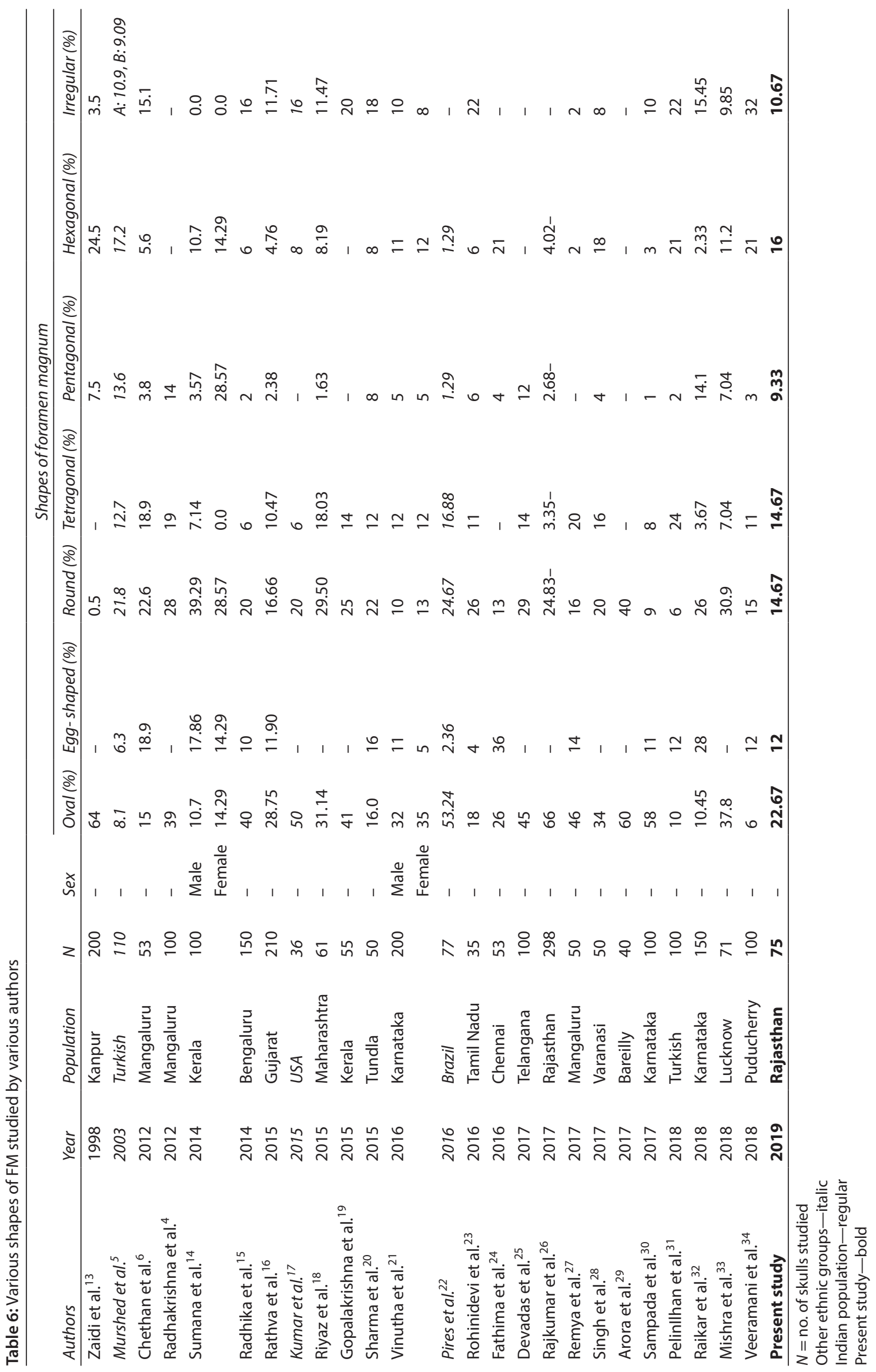


In the present study, oval-shaped FM was the commonest shape, which is comparable to findings of Indian researchers, Zaidi et al., Radhakrishna et al., Radhika et al., Rathva et al., Riyaz et al., Gopalkrishna et al., Vinutha et al., Devadas et al., Rajkumar et al., Remya et al., Singh et al., Arora et al., Sampada et al., and Mishra et al.

In the present study, the oval-shape was observed in $22.67 \%$ of dry skull specimens in contrast to highest $64 \%$ reported by Zaidi et al. and lowest $6 \%$ reported by Veeramani et al. (Tables 7 and 8 ).

The mean anteroposterior diameter observed in the present study was $35.11 \mathrm{~mm}$, which is comparable to findings of ethnic researchers, Olivier et al., Mursed et al., Suazo et al., Monoel et al., and Lyrtizis et al. They observed the mean values of the anteroposterior diameter as $35.7 \mathrm{~mm}, 35.6 \mathrm{~mm}, 35.9 \mathrm{~mm}, 35.6 \mathrm{~mm}$ (in female), $35.7 \mathrm{~mm}$ (in male) and $35.1 \mathrm{~mm}$ (in female), and 35.05 $\mathrm{mm}$, respectively.

The mean transverse diameter reported in the present study was $29.35 \mathrm{~mm}$, which is similar to findings of ethnic researchers, Suazo et al., Monoel et al., Kumar et al., Lyrtizis et al., Pires et al., and Pelimllhan et al., i.e., $29.5 \mathrm{~mm}, 29.5 \mathrm{~mm}$ (in female), $29.4 \mathrm{~mm}$, $29 \mathrm{~mm}, 29.49 \mathrm{~mm}$ (in female), $30.19 \mathrm{~mm}, 28.62 \mathrm{~mm}$, and $29.73 \mathrm{~mm}$, respectively.

The mean anteroposterior diameter observed in the present study was $35.11 \mathrm{~mm}$, which is comparable to findings of Indian researchers, Kanchan et al., Radhika et al., Sahoo et al., Rohinidevi et al., Arora et al., Sampada et al., Veeramani et al., and Feridoz et al. They observed the mean values of the anteroposterior diameter as

Table 7: Anteroposterior and transverse diameter of FM of ethnic groups

\begin{tabular}{|c|c|c|c|c|c|c|}
\hline Authors & Year & Population & $N$ & Sex & $A P D \pm S D(\mathrm{~mm})$ & $T D \pm S D(\mathrm{~mm})$ \\
\hline Olivier et al. ${ }^{1}$ & 1975 & French & 125 & - & $35.7 \pm 2.72$ & $30.34 \pm 2.15$ \\
\hline Mursed et al..$^{5}$ & 2003 & Turkish & 110 & - & $35.9 \pm 3.29$ & $30.4 \pm 2.59$ \\
\hline \multirow[t]{2}{*}{ Suazo et al. ${ }^{35}$} & 2009 & Brazil & 211 & Male & $36.5 \pm 2.6$ & $30.6 \pm 2.5$ \\
\hline & & & & Female & $35.6 \pm 2.5$ & $29.5 \pm 1.9$ \\
\hline \multirow[t]{2}{*}{ Monoel et al. ${ }^{11}$} & 2009 & Brazil & 215 & Male & $35.7 \pm 0.29$ & $30.3 \pm 0.20$ \\
\hline & & & & Female & $35.1 \pm 0.33$ & $29.4 \pm 0.23$ \\
\hline Gruber et al. ${ }^{36}$ & 2009 & Europe & 348 & - & $36.6 \pm 2.8$ & $31.1 \pm 2.7$ \\
\hline Tubbs et al. ${ }^{12}$ & 2011 & Spanish & 13 & - & 31 & 27 \\
\hline \multirow[t]{2}{*}{ Kumar et al. ${ }^{17}$} & 2015 & USA & 36 & Male & $36.78 \pm 0.0 .35$ & $30.05 \pm 0.54$ \\
\hline & & & & Female & $33.22 \pm 0.49$ & $29.49 \pm 04$ \\
\hline Lyrtizis et al. ${ }^{37}$ & 2016 & Greek & 141 & - & $35.05 \pm 2.57$ & $30.19 \pm 2.69$ \\
\hline Pires et al. ${ }^{22}$ & 2017 & Brazil & 77 & - & $34.23 \pm 2.54$ & $28.62 \pm 2.83$ \\
\hline \multirow[t]{2}{*}{ Chovalopoulou et al. ${ }^{38}$} & 2017 & Greece & 154 & Male & $36.69 \pm 2.47$ & $32.48 \pm 2.70$ \\
\hline & & & & Female & $34.87 \pm 2.41$ & $30.62 \pm 2.18$ \\
\hline Farid et al. ${ }^{39}$ & 2018 & Egyptian & 75 & & $47.1 \pm 03.4$ & $43.6 \pm 2.5$ \\
\hline Pelinllhan et al. ${ }^{31}$ & 2018 & Turkish & 100 & & $35.18 \pm 2.94$ & $29.73 \pm 2.54$ \\
\hline Present study & 2019 & Rajasthan & 75 & - & $35.11 \pm 3.12$ & $29.35 \pm 3.46$ \\
\hline
\end{tabular}

$N=$ no. of skulls studied

Indian population-regular

Present study—bold

Table 8: Anteroposterior and transverse diameter of FM of Indian population

\begin{tabular}{|c|c|c|c|c|c|c|}
\hline Authors & Year & Population & $N$ & Sex & $A P D \pm S D(\mathrm{~mm})$ & $T D \pm S D(\mathrm{~mm})$ \\
\hline Mahajan et al. ${ }^{40}$ & 2011 & Chandigarh & 126 & - & $32.83 \pm 2.62$ & $27.47 \pm 2.25$ \\
\hline Radhkrishna et al. ${ }^{4}$ & 2012 & Mangaluru & 100 & - & $34.04 \pm 2.36$ & $28.63 \pm 1.89$ \\
\hline Chethan et al. ${ }^{6}$ & 2012 & Mangaluru & 53 & - & $31 \pm 2.4$ & $25.2 \pm 2.4$ \\
\hline \multirow[t]{2}{*}{ Jain et al. ${ }^{41}$} & 2013 & Moradabad (North Indian) & 68 & Male & $36.9 \pm 0.2$ & $31.5 \pm 0.27$ \\
\hline & & & & Female & $32.9 \pm 0.3$ & $29.5 \pm 0.28$ \\
\hline \multirow[t]{2}{*}{ Kanchan et al. ${ }^{42}$} & 2013 & Mangaluru & 118 & Male & $34.51 \pm 2.77$ & $33.60 \pm 2.63$ \\
\hline & & & & Female & $27.36 \pm 2.09$ & $26.74 \pm 2.36$ \\
\hline Patel et al. ${ }^{43}$ & 2014 & Surat & 100 & - & 42.2 & 28.29 \\
\hline \multirow[t]{2}{*}{ Shepur et al. ${ }^{44}$} & 2014 & Karnataka & 150 & Male & $33.40 \pm 2.60$ & $28.50 \pm 2.20$ \\
\hline & & & & Female & $33.10 \pm 2.70$ & $27.30 \pm 2.00$ \\
\hline Radhika et al. ${ }^{15}$ & 2014 & Bengaluru & 150 & - & $35.30 \pm 2.7$ & $29.49 \pm 2.6$ \\
\hline Ganapathy et al. ${ }^{45}$ & 2014 & Puducherry & 100 & & 33.9 & 28.7 \\
\hline \multirow[t]{2}{*}{ Vedanayagam et al. ${ }^{46}$} & 2015 & Chennai & 420 & Male & $18.4 \pm 0.7$ & $28.2 \pm 0.6$ \\
\hline & & & & Female & $17.6 \pm 1.0$ & $21.8 \pm 0.7$ \\
\hline Rathva et al. ${ }^{16}$ & 2015 & Gujarat & 210 & Male & $33.5 \pm 0.45$ & $22.5 \pm 0.20$ \\
\hline
\end{tabular}


Contd...

\begin{tabular}{|c|c|c|c|c|c|c|}
\hline Authors & Year & Population & $N$ & Sex & $A P D \pm S D(\mathrm{~mm})$ & $T D \pm S D(\mathrm{~mm})$ \\
\hline & & & & Female & $31.0 \pm 0.30$ & $20.4 \pm 0.15$ \\
\hline Sahoo et al. ${ }^{47}$ & 2015 & Orissa & 150 & & $35.30 \pm 2.709$ & $29.49 \pm 2.572$ \\
\hline Riyaz et al. ${ }^{18}$ & 2015 & Maharashtra & 61 & & $33.4 \pm 2.5$ & $28.5 \pm 2.2$ \\
\hline Khanday et al. ${ }^{48}$ & 2016 & Chennai & 60 & & 36.8 & 30.9 \\
\hline Jasuja et al..$^{49}$ & 2016 & Mumbai & 100 & & $34.13 \pm 2.73$ & $27.82 \pm 3.32$ \\
\hline Fathima et al. ${ }^{24}$ & 2016 & Chennai & 53 & & 38.22 & 35.15 \\
\hline Rohinidevi et al. ${ }^{23}$ & 2016 & Tamil Nadu & 35 & & 34.80 & 28.5 \\
\hline Naqshi et al. ${ }^{50}$ & 2017 & Srinagar & 25 & & $31.6 \pm 0.21$ & $26.5 \pm 0.21$ \\
\hline Singh et al. ${ }^{28}$ & 2017 & Varanasi & 50 & & $33.76 \pm 2.18$ & $28.09 \pm 1.92$ \\
\hline Rajkumar et al. ${ }^{26}$ & 2017 & Rajasthan & 298 & & $33.98 \pm 2.75$ & $28.16 \pm 2.15$ \\
\hline Remya et al. ${ }^{27}$ & 2017 & Mangaluru & 50 & & $33.64 \pm 0.228$ & $27.04 \pm 0.214$ \\
\hline Arora et al. ${ }^{29}$ & 2017 & Bareilly & 40 & & $35.42 \pm 3.22$ & $27.90 \pm 2.58$ \\
\hline Sampada et al. ${ }^{30}$ & 2017 & Karnataka & 100 & & $34.84 \pm 2.32$ & 29.391 .73 \\
\hline \multirow[t]{2}{*}{ Veeramani et al. ${ }^{34}$} & 2018 & Puducherry & 100 & Male & $37.0 .3 \pm 0.3$ & $33 \pm 0.23$ \\
\hline & & & & Female & $35.23 \pm 0.23$ & $32 \pm 0.43$ \\
\hline Ashwini et al. ${ }^{51}$ & 2018 & Karnataka & 162 & & $33 \pm 1.4$ & $27 \pm 1.6$ \\
\hline Mishra et al. ${ }^{33}$ & 2018 & Lucknow & 71 & & $34.09 \pm 2.33$ & $28.22 \pm 2.19$ \\
\hline Raikar et al. ${ }^{32}$ & 2018 & Bengaluru & 150 & & $34.19 \pm 3.57$ & $31.77 \pm 3.59$ \\
\hline Feridoz et al. ${ }^{52}$ & 2018 & Chennai & 50 & & $35 \pm 2.8$ & $29.4 \pm 2.9$ \\
\hline Present study & 2019 & Rajasthan & 75 & - & $35.11 \pm 3.12$ & $29.35 \pm 3.46$ \\
\hline
\end{tabular}

$N=$ no. of skulls studied

Indian population-regular

Present study—bold

Table 9: Foramen magnum index

\begin{tabular}{lllllr}
\hline Authors & Year & Population & N & Sex & FMI \\
\hline Chethan et al. $^{6}$ & 2012 & Mangaluru & 53 & - & $1.2 \pm 0.1$ \\
Radhika et al. $^{15}$ & 2014 & Bengaluru & 150 & - & $1.20 \pm 0.1075$ \\
Sahoo et al. $^{47}$ & 2015 & Orissa & 150 & - & $1.2028 \pm 0.1075$ \\
Dubey et al. $^{55}$ & 2017 & Sagar and Jabalpur & 80 & Male & $1.18 \pm 0.11$ \\
& & & & Female & $1.16 \pm 0.07$ \\
Pelinllhan et al. $^{31}$ & 2018 & Turkish & 100 & Male & $1.19 \pm 0.09$ \\
Veeramani et al. $^{34}$ & 2018 & Puducherry & 100 & Female & $1.13 \pm 0.11$ \\
& & & & - & $1.09 \pm 0.15$ \\
Present study & $\mathbf{2 0 1 9}$ & Rajasthan & $\mathbf{7 5}$ & & $\mathbf{1 . 2 0 8} \pm \mathbf{0 . 1 5}$ \\
\hline
\end{tabular}

$N=$ no. of skulls studied

Other ethnic groups-italic

Indian population-regular

Present study—bold

$34.51 \mathrm{~mm}, 35.30 \mathrm{~mm}, 35.30 \mathrm{~mm}, 34.80 \mathrm{~mm}, 35.42 \mathrm{~mm}, 34.84 \mathrm{~mm}$, $35.23 \mathrm{~mm}$ (in female), and $35 \mathrm{~mm}$, respectively.

The mean transverse diameter was reported as $29.35 \mathrm{~mm}$ in the present study, which is similar to the findings of Indian researchers, Radharkrishna et al., Jain et al., Shepur et al., Radhika et al., Vedanayagam et al., Saini et al., Sahoo et al., Riyaz et al., Rohinidevi et al., Sampada et al., Mishra et al., and Feridoz et al., i.e., $28.63 \mathrm{~mm}$, $29.5 \mathrm{~mm}$ (in female), $28.50 \mathrm{~mm}$ (in male), $29.49 \mathrm{~mm}, 28.5 \mathrm{~mm}$, $29.39 \mathrm{~mm}, 28.22 \mathrm{~mm}$, and $29.4 \mathrm{~mm}$, respectively.

The foramen magnum index of 1.2 has been reported in Karnataka population (Chethan et al. and Radhika et al.) and Orissa population (Sahoo et al.) (Table 9).

In the present study in Rajasthan population, FMI was also 1.2.
The foramen magnum index was relatively lower in Madhya Pradesh population (Dubey et al.) and Puducherry population (Veeramani et al.). In ethnic group studies only, Pelinllhan et al. (Turkish population) have reported lower FMI.

In the present study (Jaipur region, Rajasthan), area was calculated as $813.94 \mathrm{~mm}^{2}$, which is similar to the study of Jaitley et al. in female $\left(812.22 \mathrm{~mm}^{2}\right)$ in the Indore region of Madhya Pradesh (Table 10).

The highest area was reported by Faridoz et al., i.e., $1598 \mathrm{~mm}^{2}$, and the least was reported by Khanday et al., i.e., $576 \mathrm{~mm}^{2}$.

In another study by Rajkumar et al., the Udaipur region of Rajasthan has reported much lower area of FM $\left(754.32 \mathrm{~mm}^{2}\right)$. 
Table 10: Area of FM

\begin{tabular}{|c|c|c|c|c|c|}
\hline Authors & Year & Population & $N$ & Sex & Area \\
\hline \multirow[t]{2}{*}{ Murshed et al. ${ }^{5}$} & 2003 & Turkish & 110 & Male & $931.7 \pm 144.29$ \\
\hline & & & & Female & $795.0 \pm 99.32$ \\
\hline \multirow[t]{2}{*}{ Sing and Talwar ${ }^{54}$} & 2013 & Chandigarh & 50 & Male & $733.32 \pm 9.40$ \\
\hline & & & & Female & $692.64 \pm 13.20$ \\
\hline Patel et al. ${ }^{43}$ & 2014 & Surat & 100 & - & 756.37 \\
\hline \multirow[t]{2}{*}{ Shepur et al. ${ }^{44}$} & 2014 & Karnataka & 150 & Male & $862.0 \pm 119$ \\
\hline & & & & Female & $758.0 \pm 109$ \\
\hline Sharma et al. ${ }^{20}$ & 2015 & Tundla & 50 & - & 970.57 \\
\hline \multirow[t]{2}{*}{ Rathva et al. ${ }^{16}$} & 2015 & Gujarat & 210 & Male & $853 \pm 020$ \\
\hline & & & & Female & $718 \pm 015$ \\
\hline \multirow[t]{2}{*}{ Kumar et al. ${ }^{17}$} & 2015 & USA & 36 & Male & $876.88 \pm 88.83$ \\
\hline & & & & Female & $776.87 \pm 68.51$ \\
\hline Riyaz et al. ${ }^{18}$ & 2015 & Maharashtra & 61 & - & 747.92 \\
\hline \multirow[t]{2}{*}{ Jaitley et al. ${ }^{53}$} & 2016 & Indore & 280 & Male & $916 \pm 145$ \\
\hline & & & & Female & $812.22 \pm 95.9$ \\
\hline Khanday et al. ${ }^{48}$ & 2016 & Chennai & 60 & - & 576 \\
\hline Lyrtzis Ch et al. ${ }^{37}$ & 2016 & Greek & 141 & - & $778.15 \pm 125.11$ \\
\hline Fatima et al. ${ }^{24}$ & 2016 & Chennai & 53 & - & 1102 \\
\hline Rohinidevi et al. ${ }^{23}$ & 2016 & Tamil Nadu & 35 & - & 820.53 \\
\hline Naqshi et al. ${ }^{50}$ & 2017 & Srinagar & 25 & - & $660 \pm 090$ \\
\hline \multirow[t]{2}{*}{ Devadas et al. ${ }^{25}$} & 2017 & Telangana & 100 & Male & 1089.99 \\
\hline & & & & Female & 837.84 \\
\hline Singh et al. ${ }^{28}$ & 2017 & Varanasi & 50 & - & $834.45 \pm 75.79$ \\
\hline Rajkumar et al. ${ }^{26}$ & 2017 & Rajasthan & 298 & - & $754.32 \pm 105.16$ \\
\hline Remya et al. ${ }^{27}$ & 2017 & Mangaluru & 50 & - & $714.99 \pm 0.844$ \\
\hline \multirow[t]{2}{*}{ Chovalopoulou et al..$^{38}$} & 2017 & Greek & 154 & Male & $938.12 \pm 123.20$ \\
\hline & & & & Female & $839.82 \pm 99.91$ \\
\hline Sampada et al. ${ }^{30}$ & 2017 & Karnataka & 100 & - & $803.8 \pm 83.42$ \\
\hline Raikar et al. ${ }^{32}$ & 2018 & Bengaluru & 150 & - & $800.72 \pm 86.85$ \\
\hline Faridoz et al. ${ }^{52}$ & 2018 & Chennai & 50 & - & $1598 \pm 182$ \\
\hline Present study & 2019 & Rajasthan & 75 & - & $813.94 \pm 146.40$ \\
\hline
\end{tabular}

$N=$ no. of skulls studied

Other ethnic groups-italic

Indian population-regular

Present study—bold

\section{Conclusion}

The morphological and morphometric analysis of FM and its variations is important not only to anatomists but also to the neurosurgeons, anesthetists, orthopedicians, and radiologists. These variations have become significant because of newer imaging techniques such as computed tomography and magnetic resonance imaging in the field of diagnostic medicine.

This study will also be a help to forensic medicine experts since ethnic variations as seen and compared with research of other ethnic region population researchers may help in identification of different races.

\section{References}

1. dE Oliveira $E$, Rhoton AL Jr, et al. Microsurgical anatomy of the region of the foramen magnum. Surg Neurol 1985;24(3):293-352. DOI: 10.1016/0090-3019(85)90042-4.
2. Scheuer L, Black S. The Juvenile Skeleton. London: Elsevier; 2004. pp. 1-19.

3. Romanes GJ. Cunmningham's text book of anatomy, 12th ed., Oxford: Oxford University Press; 1981. p. 114.

4. Radhakrishna S, Shivarama CH, et al. Morphometric analysis of foramen magnum for sex determination in South Indian Population. Nite University Journal of Health Science 2012;2(1):20-22.

5. Murshed KA, Cicekcibasi AE, et al. Morphometric evaluation of the foramen magnum variations in its shape: a study on computerized tomographic images of normal adults. Turk J med Sci 2003;33(1): 301-306.

6. Chethan P, Prakash KG, et al. Morphological analysis and Morphometry of the Foramen Magnum: An Anatomical Investigation. Turkish Neurosurgery 2012;22(4):416-419. DOI: 10.5137/1019-5149. JTN.4297-11.1.

7. Bannister LH, Berry MM, et al. Gray's anatomy the anatomical basis of medicine and surgery, 38th ed., Edinburgh: Churchill Livingstone; 1995. pp. 567-568. 
8. Hecht TJ, Horton WA, et al. Growth of the foramen magnum in achondroplasia. Am J Med Genet 1989;32:528-535. DOI: 10.1002/ ajmg.1320320421.

9. Reich JB, Sierra J, et al. Magnetic resonance imaging measurements and clinical changes accompanying transtentorial and foramen magnum brain herniation. Annals of Neurology 1993;33:159-170. DOI: 10.1002/ana.410330205.

10. Ropper AH. MRI demonstration of the major feature of herniation. J Neurol Neurosurg Psychiatry 1993;56:932-935. DOI: 10.1136/ jnnp.56.8.932.

11. Manoel C, Prado FB, et al. Morphometric analysis of the foramen magnum in human skulls of Brazilian individuals: its relation to gender. Braz J Morphol Sci 2009;26(2):104-108.

12. Tubbs RS, Griessenauer CJ, et al. Morphometric analysis of the foramen magnum: an anatomic study. Neurosurgery 2010;66: 385-388. DOI: 10.1227/01.NEU.0000363407.78399.BA.

13. Zaidi SH, Dayal SS. Variations in the shape of foramen magnum in Indian skulls. Anat Anz 1988;167(4):338-340.

14. Sumana R, Kirubhanand C, et al. Morphometric study of the foramen magnum in adult Human skulls in South Indian Population. Int J Anat Sci 2014;5(2):43-45.

15. Radhika PM, Shetty S, et al. Morphometric study of the foramen magnum in adult human skulls in Indian Population. Asian J Med Clin Sci 2014;3(1):68-72.

16. Rathva A, Shah K, et al. Morphometry and sexual dimorphism of human skull foramen magnum. Int J Recent Trends Sci Technol 2015;15(2):379-386.

17. Kumar A, Dave $M$, et al. Morphometric evaluation of foramen magnum in dry human skulls. Int J Anat Res 2015;3(2):1015-1023. DOI: 10.16965/ ijar.2015.154.

18. Riyaz ZH, Siddiqui AA. Morphometric study of foramen magnum in human skulls. Int J Recent Trends Sci Technol 2015;17(1): 28-31.

19. Gopalakrishna K, Rathna BS. The craniometric study of foramen magnum of Indian population and variations in its dimensions. Int J Allied Med Sci Clin Res 2015;3(2):205-211.

20. Sharma S, Sharma AK, et al. Morphometric evolution of foramen magnum and variation in its shape and size: a study on Human dried skull. Int J Anat Res 2015;3(3):1399-1403. DOI: 10.16965/ijar. 2015.246.

21. Vinutha SP, Shubha R. Morphometry and sexual dimorphism in foramen magnum: a study of human skull bones. Int J Anat Res 2016;4(3):2593-2599.

22. Pires LAS, Teixeira AR, et al. Morphometric aspects of the foramen magnum and the orbit in Brazilian dry skulls. Int J Med Res Health Sci 2016;5(4):34-42.

23. Rohinidevi M, Vimala V. Morphometric analysis of foramen magnum and variations in its shape in dried human adult skulls. Int J Anat Res 2016;4(3):2670-2673. DOI: 10.16965/ijar.2016.298.

24. Fathima F, Babu KY. Evaluating the shape of foramen magnum and overlapping of occipital condyle on the foramen. Int J Sci Res 2016;5(9):1078-1082.

25. Devadas P, Rao MJ, et al. Study on the Morphometric analysis of the foramen magnum as an indicator for sex determination. Int J Anat Res 2017;5(3.1):4163-4167. DOI: 10.16965/ijar.2017.274.

26. Rajkumar, Kattimuthu $P$, et al. Morphometric analysis of foramen magnum of dry human skulls in North Indian population. Int J Anat Res 2017;5(1):3480-3484. DOI: 10.16965/ijar.2016.495.

27. Remya K, Rathnakar $P$, et al. Evaluation of foramen magnum in dry human skulls of Dakshina Kannada District. Int J Anat Res 2017;5(4.1):4488-4491.

28. Singh KC, Rai G, et al. Morphological variations of the foramen magnum in adult human dry skull in Eastern UP (India) Population. Int J Med Res 2017;3(2):205-208.

29. Arora S, Sharma SK, et al. Morphometry and surgical importance of foramen magnum. Int J Anat Res 2017;5(1):3464-3469.
30. Sampada PK, Poornima B, et al. Morphometric and Morphological study of foramen magnum in dried human skull bones. Int J Anat Res 2017;5(2.1):3682-3686. DOI: 10.16965/ijar.2017.139.

31. Ilhan P, Kayhan B, et al. Morphological analysis of occipital condyles and foramen magnum as a guide for Lateral Surgical Approaches. MOJ Anat and Physiol 2017;3(6):188-194.

32. Raikar NA, Meundi MA, et al. Sexual dimorphism in foramen magnum dimensions in the South Indian Population: a digital submentovertex radiographic study. J Forensic Dent Sci 2016;8:180-187. DOI: 10.4103/0975-1475.195104.

33. Mishra AK, Pandey SB, et al. Morphometric study of foramen magnum of skull in population of Uttar Pradesh. Int J Anat Res 2018;6(2.2): 5186-5190. DOI: 10.16965/ijar.2018.150.

34. Veeramani R, Manjunath KY, et al. Morphological and Morphometric study of variations in the shape and size of the foramen magnum of human skulls. Int J Anat Radiol Surgery 2018;7(2):1-8.

35. Suazo GIC, Russo PP, et al. Sexual Dimorphism in the foramen magnum dimensions. Int J Morphol 2009;27(1):21-23.

36. Gruber $P$, Henneberg $M$, et al. Variability of human foramen magnum size. The Anatomical Recrd 2009;292:1713-1719. DOI: 10.1002/ ar.21005.

37. Lyrtzis C, Piagkou M, et al. Foramen Magnum, Occipital Condyles, and Hypoglossal canals Morphometry: Anatomical study with clinical implications. Folia Morphol 2016;76(3):446-457. DOI: 10.5603/ FM.a2017.0002.

38. Chovalopoulou ME, Bertsatos A. Estimating sex of modern Greeks based on the foramen magnum region. J of Anthropology 2017; 1-7. DOI: 10.1155/2017/9129801.

39. Farid SA, Fattah IOA. Morphometric study of human adult occipital condyle, hypoglossal canal and foramen magnum in dry skull of modern Egyptians. Int J of Clinical and Developmental Anatomy 2018;4(1):19-26. DOI: 10.11648/j.ijcda.20180401.13.

40. Mahajan D, Agnihotri G, et al. An anatomical perspective of human occipital condyles and foramen magnum with neurosurgical correlates. Int J of Exp Clin Anatomy 2011;6(7):29-33.

41. Jain SK, Choudhary AK, et al. Morphometric evaluation of foramen magnum for sex determination in a documented North Indian sample. J Evol Med Dent Sci 2013;2(42):8093-8098. DOI: 10.14260/ jemds/1425.

42. Kanchan T, Gupta A, et al. Craniometric analysis of foramen magnum for estimation of sex. Int J of Med and Health Sci 2013;7(7): 378-380.

43. Patel $R$, Mehta CD. Morphometric study of foramen magnum at the base of human skull in South Gujarat. IOSR J of Dental and Med Sc 2014;13(6):23-25. DOI: 10.9790/0853-13642325.

44. Shepur MP, Magi M, et al. Morphometric analysis of foramen magnum. Int J Anat Res 2014;2(1):249-255.

45. Ganapathy A, Sadeesh T, et al. Morphometric analysis of foramen magnum in adult human skulls and CT images. Int J Cur Res 2014;6(20):11-15.

46. Vedanayagam $T$, Sathyamurthy V. Sex determination from foramen magnum measurements-A regional study in Chennai, Tamil Nadu. Indian. J of Forensic and Community Medicine 2015;2(3):179-181.

47. Sahoo S, Giri SK, et al. Morphometric analysis of the foramen magnum and occipital condyles. Int J Pharm Sci Rev Res 2015;33(2): 198-204.

48. Khanday S, Chakaravarthy P. Morphology and Morphometry of foramen magnum. Int J of Current Res 2016;8(3): 27765-27767.

49. Jasuja VR, Kulkarni PG, et al. A Morphometric study of occipital condyles and foramen magnum in adult skull base in Western Maharashtra region of India. Int J Anat Res 2016;4(1):1846-1850. DOI: 10.16965/ijar.2015.349.

50. Naqshi BF, Shahdad S, et al. Morphological and Morphometric study of foramen magnum in dry human skulls of Kashmir. Global J for Res Analysis 2017;6(8):1-3. 
51. Ashwini C, Khona P. A Morphometrical study of foramen magnum in adult human dried skull of South Indian Population. Int J Anat Res 2018;6(1.1):4831-4835. DOI: 10.16965/ijar.2017.477.

52. Feridoz J, Babu Y. Morphometric analysis of foramen magnum. Int J Sci Dev Res 2018;3(4):302-305.

53. Jaitley $M$, Phulambrikar $T$, et al. Foramen Magnum as a tool for sexual dimorphism: a cone beam computed tomography study.
Indian J of Dental Res 2016;27:458-462. DOI: 10.4103/0970 9290.195610.

54. Singh G, Talwar I. Morphometric analysis of foramen magnum in human skull for sex determination. Hum Bio Rev 2013;2(1):29-41.

55. Dubey A, Verma SK. The anatomy occipital condyles and foramen magnum and their surgical importance: a Morphometric study. Int J Anat Res 2017;5(2.1):3780-3783. DOI: 10.16965/ijar.2017.193. 